\title{
Reliability of Daylight and Energy Demand Evaluations for Decision Making at the Conceptual Stage of Neighbourhood Design
}

\author{
Minu Agarwal ${ }^{1}$, Gerald Danseux ${ }^{1,2}$, Luisa Pastore ${ }^{1}$, Marilyne Andersen ${ }^{1}$ \\ ${ }^{1}$ Laboratory Of Integrated Performance In Design (LIPID), École Polytechnique Fédérale de \\ Lausanne (EPFL), Lausanne, Switzerland \\ ${ }^{2}$ Institut National des Sciences Appliquées de Strasbourg, France
}

\begin{abstract}
When conducting building performance simulation (BPS) at the early design stage, potential impact on design decisions is the greatest. However, the reliability of evaluations resulting from early design stage BPS models may suffer given that building attributes likely to be influential on a neighbourhood project's performance are often undecided. In this paper, we investigated the risk of making incorrect early design decisions by comparing performance estimations of daylight potential (sDA) and energy demand for heating/cooling of a range of neighbourhood massing schemes at low and high level of design development. The approach consisted of isolating and measuring the risk of performance loss (i.e. of being wrong in "ranking" the neighbourhood's overall daylight or energy performance) due to unknown building façade attributes. Cooling demand evaluations were found to be most reliable $(92 \%$ cases resulting in low risk of performance loss due to unknown façade attributes). Spatial Daylight Autonomy (sDA) and heating demand based assessments resulted in lower reliability $(78 \%, 85 \%$ low risk cases respectively).
\end{abstract}

\section{Introduction}

Daylight potential and energy demand for heating/ cooling are amongst the main performance evaluation metrics for building projects. At the onset of a neighbourhood design process, they are often used as criteria for identifying high performing neighborhood forms and building typologies. Such a process may rely on BPS based tools such as UMI (C. Reinhart et al. 2013), CitySim (Darren Robinson et al. 2009), urban solar/daylight availability (Compagnon 2004), SunTool (D. Robinson et al. 2007), or UrbanSOLve (Nault 2016). These tools/methods are meant for exploring and making decisions regarding broad neighborhood/urban scale geometrical characteristics. However, currently these tools do not attach any reliability or accuracy measures to performance evaluations even though a large number of building level design decisions impacting daylight and energy performance are unknown at the early design stage. For example, Hester et. al (Hester, Gregory, and Kirchain 2017) found that energy demand stabilized only after $40 \%$ (out of 22) design factors had been determined when exploring the early design solution space for a single family home in Chicago. Some of these decisions were conceptual design decisions (total built area) while others such at attic U-value may typically be decided only in later design stages.

A recent position paper calls for reporting performance values from BPS tools with greater precision (J. A. Clarke and Hensen 2015) in order to better support design decision making. To illustrate more specifically, Tregenza (Tregenza 2017) found that internal horizontal illuminance (the principal input towards calculation of sDA) varies by +/- 20\% if indoor/outdoor surface reflectance properties and glazing light transmittance properties are unknown. He further suggests that "conclusions that could be drawn from a statement that the illuminance at a workplace is 300 lux are different from those implied by the statement that the illuminance is $300+/-60$ lux".

Uncertainties in absolute performance evaluations such as those mentioned above are known, acknowledged and to a large extent unavoidable at the early design stage. A common argument in favour of conducting performance evaluations at the early design stage is that the evaluations at this stage are relative in nature and the intent is to identify the design with the highest performance potential. Thus researchers have tried to evaluate metrics based on their ability to differentiate between designs (Nezamdoost and Wymelenberg 2016) and also sensitivity to design decisions that are typically undecided at the early design stage. For example, Brembrilla et. al. (Brembilla, Hopfe, and Mardaljevic 2017) measured sensitivity of common daylight metrics such as sDA, Useful Daylight Illuminance (UDI) and Total Annual Illuminance (TAI) among others to building interior related design features unknown at the early design stage, and to modelling methods used. Hopfe et al. (Hopfe, Augenbroe, and Hensen 2013) proposed improvements to existing decision making methods to include uncertainty in performance evaluations during the design process. However, measures of uncertainty and sensitivity cannot help a decision maker understand the risk involved in a decision. Risk is a subset of uncertainty in possible decision outcomes, comprising those outcomes which result in loss (Smith and Merritt 2002). When making a binary choice, a decision maker may not be in a position to eliminate or even reduce uncertainty, but would still like to avoid incurring a loss as a result of the decision. In this paper, we thus measure reliability of early design decision by measuring the risk of performance loss resulting from design decisions made with unknown 
façade characteristics. More specifically we have the following objectives:

1. Identify and use measures of risk to assess reliability of early design decisions.

2. Present the risk of performance loss in relative performance evaluations at the early design stage due to unknown building façade attributes, i.e. when only broad geometrical formulation of the neighborhood is available.

\section{Methodology}

Within a pool of realistic neighbourhood design scenarios for a given site at a fixed density (floor area ratio) of 1.0, we produce pairs of competing massing design proposals. A relatively 'low' density was chosen so that the (vertical) facade surfaces are likely have 'high' sky exposure: indeed, if no effect of façade detail on design decisions is observed at this density, then there is a low chance of observing such an effect at higher densities where form tends to play a greater role in determining neighborhood level daylight autonomy and energy demand (Sattrup and Strømann-Andersen 2013).

We then compare the daylight 'potential' (represented by sDA), annual heating and cooling demand between two massing schemes, first with no explicit information regarding façade design, i.e. at a minimum façade level of detail (min-fLOD), and then at a high façade level of detail (high-fLOD). Existing frameworks ("LOD | BIMForum"; Biljecki, Ledoux, and Stoter 2016) for model level-of-detail could not be used as they were not found to be in line with the input requirements of detailed thermal and annual daylight simulations. In this study façades are modelled at the min-fLOD to represent default façade related inputs that are likely to be used in absence of any specific façade related design information (Table 1). At high-fLOD we model various façade design resulting from many possible design paths that could be taken. More specifically, we enumerated 48 high-fLOD distinct façade design possibilities (Refer to Figure 1 for process followed and Table 1 for range of inputs).

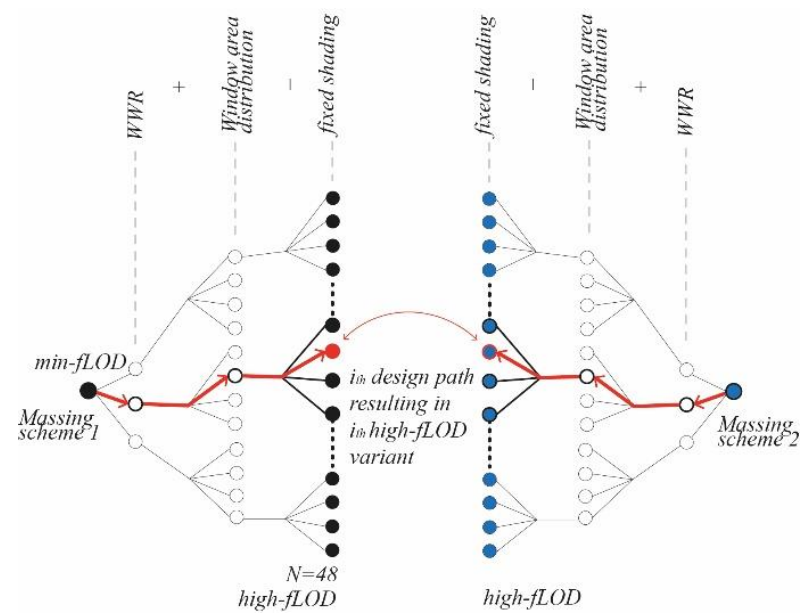

Figure 1: Schematic diagram showing transition from min-to-high fLOD
Overall, the developed approach towards examining reliability of early design stage decisions can be described as follows: Performance comparison of the two massing schemes is first done at low-fLOD. A higher performing form is then identified. We then formulate high-fLOD variants of the two massing schemes into pair-wise comparison to identify the number of cases in which the high performing form at low-fLOD is no longer found to be the high performing form at high-fLOD. Such cases represent the risk of "incorrect ranking". Details regarding the simulation method used and formulation of cases of "incorrect ranking" into an overall risk assessment are described in the following subsections.

Table 1: Façade inputs at min-fLOD and high-fLOD

\begin{tabular}{|c|c|c|}
\hline Façade property & min-fLOD & High-fLOD \\
\hline \multicolumn{3}{|c|}{ Façade design attributes } \\
\hline WWR & $30 \%$ & $20 \%, 30 \%, 40 \%$ \\
\hline $\begin{array}{l}\text { Distribution of glazed } \\
\text { area per facade }\end{array}$ & \begin{tabular}{|l} 
Uniform, \\
$30 \%$
\end{tabular} & Varies $60 \%$ to $10 \%$ \\
\hline Active shading & none & $\begin{array}{l}\text { Manual operation model } \\
\text { with fully open and fully } \\
\text { closed positions. }\end{array}$ \\
\hline Fixed shading & none & \begin{tabular}{|l|l|} 
Present, depth varies \\
from $1.2 \mathrm{~m}-2.4 \mathrm{~m}$
\end{tabular} \\
\hline \multicolumn{3}{|c|}{ Window size and placement } \\
\hline $\begin{array}{l}\text { Number of window } \\
\text { units per facade }\end{array}$ & 3 or higher & Same as min- fLOD \\
\hline Window height & $2.0 \mathrm{~m}$ & Same as min-fLOD \\
\hline Window width & $\begin{array}{|ll|}0.5 \quad \mathrm{~m} & \text { or } \\
\text { higher }\end{array}$ & \begin{tabular}{|lll}
$\begin{array}{l}\text { Same } \\
\text { model }\end{array}$ & as min-fLOI \\
\end{tabular} \\
\hline Sill height & $.25 \mathrm{~m}$ & \begin{tabular}{|lll}
$0.25 \quad \mathrm{~m} \quad(0.05 \mathrm{~m}$ & when \\
balconies present $)$ & \\
\end{tabular} \\
\hline \multicolumn{3}{|l|}{ Glazing properties } \\
\hline \begin{tabular}{|ll} 
visible & light \\
transmittance
\end{tabular} & 0.6 & 0.6 \\
\hline SHGC & 0.58 & 0.58 \\
\hline U-Value & 1.0 & 1.0 \\
\hline
\end{tabular}

\section{Virtual enrichment of façade details}

Façade design factors that influence the amount of daylight and solar irradiation intake to the building interior, namely, window size, window orientation, active blinds and balconies are included in the detail enrichment workflow. By increasing the level of detail on these façade design parameters, we are able to explore the possible effectiveness that can be achieved in taking advantage of vertical surfaces on each massing scheme for solar gains and daylight access. Thermal and light transmission properties of all glazed and opaque envelope parts, are kept constant and in conformity with climate appropriate building energy norms (SIA 2016). Surface reflectance properties of the built context also influences the daylight and irradiation intake but is kept constant as it is typically outside the purview of the designer. All surface reflectance properties and glazing transmission properties are kept in line with LM-83-12 standard (IESNA 2012) for calculating sDA. Blind operation for both thermal and daylight simulations is as per BLINDSWITCH-A (Van Den Wymelenberg 2012) manual blind operation model. Daylight simulations were carried out using DAYSIM (C. F. Reinhart 2012) and 


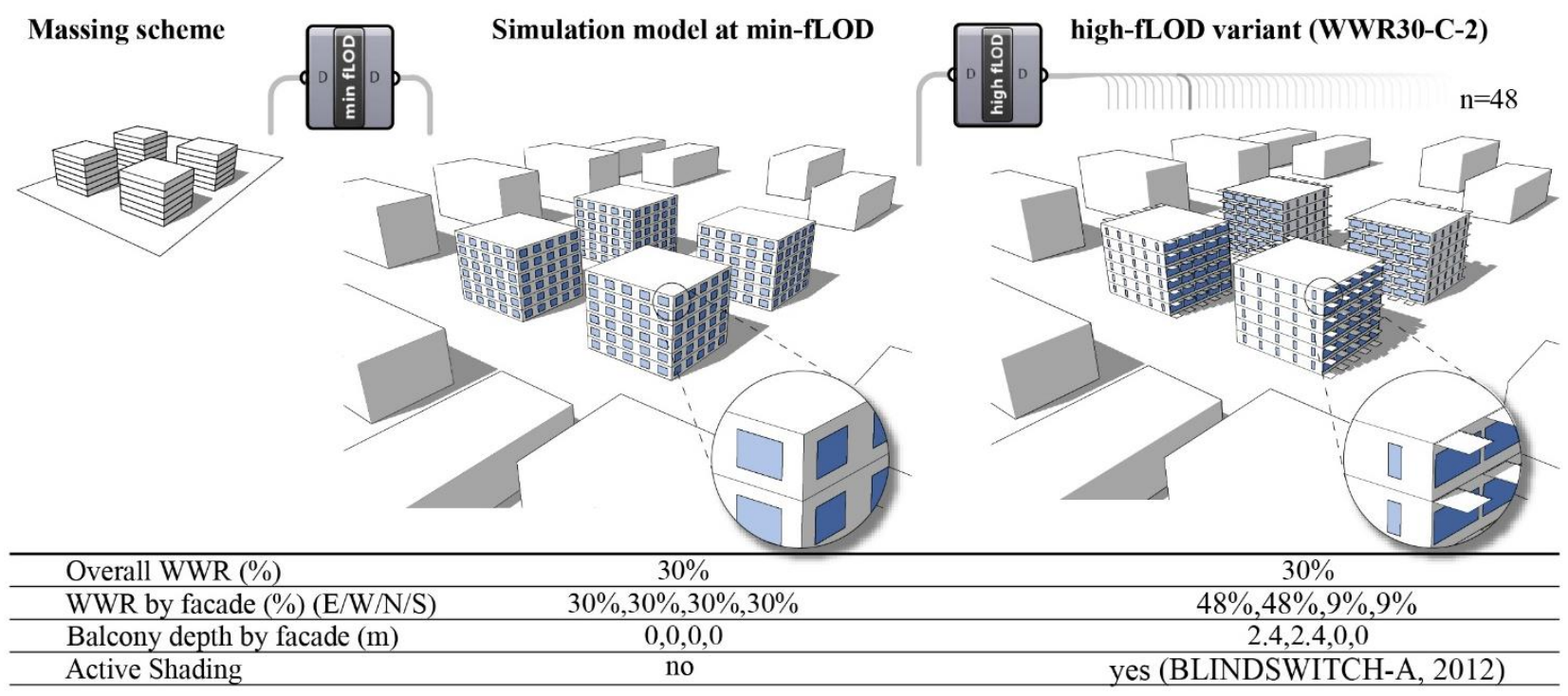

Figure 2: Grasshopper workflow application to an example massing scheme.

annual dynamic thermal simulation were carried out using EnergyPlus (Crawley et al. 2000).

Three levels of window to wall ratio (WWR), four distinct design schemes for distribution of the total window area on the various vertical surfaces and four distinct balcony types are considered $(3 \times 4 \times 4=48)$. Figure 2 shows the 'default' façade inputs for a massing scheme at min-fLOD (figure in centre), and one instance of the façade design at high-fLOD (figure on the right hand side). Note that the façade details are applied while accounting for design inter-dependencies such as balconies being assigned to facades with higher WWR and number of window divisions per façade being kept proportional to expected number of apartment units per floor, in order to produce façade schemes as rational as possible.

In all the resulting facade schemes, the window height $(2 \mathrm{~m})$ and sill height $(0.75 \mathrm{~m})$ are kept constant, irrespective of the WWR and all other factors. The only exception to this rule is allowed where balconies are present: in those cases, the window is dropped to the floor level $(+0.05 \mathrm{~m})$ to include reflection of radiation from the floor of the balcony into the building interior through a glass door/window panel. The scope of the study is limited to factors influencing intake of daylight/solar irradiation, which is the primary concern when selecting the form. Façade design factors influencing internal distribution of daylight in the building interior (such as window aspect ratio and position e.g.), which also have minimal impact on annual heating/cooling demand, are excluded.

This process is repeated for several pairs of massing schemes to ascertain the incidence rate of disagreement between design decision at low and high fLOD. The method for arriving at a design decision based on the simulated performance requires a criterion, described in the next subsection.

\section{Design Decision Criteria}

In order to choose a design massing scheme based on performance, we need a minimum performance differentiation criterion. Table 2 gives various possible performance based decision criteria that could be adopted. For this study we are presenting results based on a minimum $10 \%$ difference in sDA. If the performance difference between two massing schemes is found to be less than $10 \%$ then the difference between then is regarded as insignificant. For heating and cooling demand, the decision criteria is set at 2.8 and 3.6 $\mathrm{kWh} / \mathrm{m} 2$-year respectively.

Table 2: Potential decision criteria for $S D A$ and heating/cooling demand

\begin{tabular}{|l|l|}
\hline \multicolumn{1}{|l|}{ Possible design decision thresholds for sDA } \\
\hline $10 \%$ & $\begin{array}{l}\text { Common understanding of appreciable } \\
\text { performance difference in sDA } \\
\text { (Iversen, Svendsen, and Nielsen 2013) }\end{array}$ \\
\hline $20 \%$ & $\begin{array}{l}\text { Performance difference between } \\
\text { "acceptable" and "preferred" } \\
\text { evaluation by occupants, Additional } \\
\text { credit awarded as per LEEDv4 } \\
\text { ("LEED | USGBC") }\end{array}$ \\
\hline Possible design decision thresholds for annual heating \\
\hline $2.8 \mathrm{kWh} / \mathrm{m} 2$-year & $\begin{array}{l}\text { Performance difference between } \\
\text { compliance with SIA 380/2009 (local } \\
\text { energy lode) and MINERGIE rating }\end{array}$ \\
\hline $4.3 \mathrm{kWh} / \mathrm{m} 2$-year & $\begin{array}{l}\text { Performance difference between } \\
\text { compliance with SIA 380/2009 and } \\
\text { MINERGIE-P rating }\end{array}$ \\
\hline Possible design decision thresholds for annual cooling \\
\hline $3.6 \mathrm{kWh} / \mathrm{m} 2$-year & $\begin{array}{l}\text { Additional artificial energy demand to } \\
\text { achieve comfort category II instead of } \\
\text { III (EN 15251) }\end{array}$ \\
\hline $6.9 \mathrm{kWh} / \mathrm{m} 2$-year & $\begin{array}{l}\text { Additional artificial energy demand to } \\
\text { achieve comfort category I instead of } \\
\text { III (EN 15251) }\end{array}$ \\
\hline
\end{tabular}




\section{Measuring reliability of design-decision at min-fLOD}

Under various kinds of uncertainties (such as weather, human behaviour or inadequate design data/inaccurate data) the resulting performance of design alternatives can be viewed as distributions. As mentioned earlier, in order to make a design-decision we need to evaluate the risk involved in the decision being made under uncertainty. Normative decision theory offers the construct 'opportunity loss' which can help a decision maker isolate the risk emanating from a particular decision: in this context, the definition of opportunity loss entails comparing the actual payoff from a choice to the optimal payoff if the best possible decision was made (Savage 1951). Hubbard (Hubbard 2014) explains it as "the difference between the wrong choice you took and the best alternative available- that is, the one you would have chosen if you had the perfect information". In the context of the present paper, we interpret 'opportunity loss' as the performance loss from "un-choosing" the massing scheme, that would be chosen, if the designer knew what kind of façade he/she would design.

$\mathrm{Su}$ and Tung (Su and Tung 2012) further extended interpretation of opportunity loss for design and engineering problems using pair-wise comparison of outcomes and summing the negative payoffs weighted by their respective probability as the Expected Opportunity Loss (EOL) (Eq. 1). We use this pairing mechanism to calculate the EOL with checks for keeping the WWR and the balcony type the same for each pair. e.g. at high fLOD a design variant for Scheme A is compared to a variant of Scheme B such that the WWR and balcony type is the same as there is no reason to believe that the choice of the massing scheme would influence the WWR and balcony design. However, the choice of massing scheme is expected to influence design possibilities related to orientation of the windows and thus cross comparison across orientation related variants is permitted. We incorporate EOL in a sequential decision making scenario where the opportunity loss at high-fLOD is calculated whenever a decision is made based on the observed performance difference between the massing schemes at min-fLOD. The decision at min-fLOD is made in anticipation (of lack thereof) of an observed relative performance gain. In case a significant performance gain (performance gain $>=$ decision criterion, $d$ ) is anticipated at min-fLOD and is lost at high-fLOD due to convergence in performance of the two massing schemes, this loss of anticipated gain is also accounted in EOL. We refer to this final entity as Expected Relative Performance Loss (ERPL) in this paper.

\section{Mathematical description of expected relative performance loss (ERPL)}

First, a minimum differentiation $(d)$ based decision criteria is chosen/decided for a given metric. The performance of two design alternatives is then compared at min-fLOD. If the difference between two alternatives (A, B) at min-fLOD exceeds $d$, then a preferred design alterative (signified by $*$ ) is identified a priori.

$$
\operatorname{EOL}\left(A^{*}, B\right)=-\int_{-\infty}^{0} f_{R}(r) d r
$$

where $\operatorname{EOL}\left(\mathrm{A}^{*}, \mathrm{~B}\right)$ is the $\operatorname{EOL}$ when $\mathrm{A}$ is the preferred massing scheme and $f_{R}$ is a probability distribution function of the relative performance gain $(\mathrm{R})$ from design pairs formulated at high-fLOD. If the performance difference between $\mathrm{A}$ and $\mathrm{B}$ is smaller than the decision criteria, then the two design alternatives are regarded as equivalent and the probability of either being chosen is $0.5(\mathrm{P}(\mathrm{A})=\mathrm{P}(\mathrm{B})=0.5)$. ERPL in this case and other conditions calculated as per equation 2 . In equation 2 , $a_{\min }, b_{\min }$ are performance values of given massing schemes at min-fLOD.

\section{Analysis of results}

In order to test if a significant opportunity loss can occur due to form related design decision made at min-fLOD, we artificially extend the design process and model 48 distinct façade design possibilities on the two forms. Results are presented at three levels of observation:

1. We first examine one instance of a comparison between two massing schemes A and B (Figure 3, Box I.). The variation in relative performance values at high-fLOD is shown for all façade variants for the two forms.

2. We then present results from multiple pairs of massing schemes, showing instances of opportunity loss (Figure 3, Box II.). By looking at this set, we make observations regarding the conditions under which opportunity loss tends to occur.

3. We finally present synthesis of results from all the comparisons that we carried out on 40 massing schemes (Figure 3, Box III.). We get 780 pairs of massing schemes $\left({ }^{40} \mathrm{C}_{2}=780\right)$ and we report the overall incidence rate of high ERPL.

\section{Comparison outcomes}

Figures 4(a), (b), (c) show the performance of forms A, B at high-fLOD on sDA, annual heating and annual cooling demand. Due to space constraints, in figure 4, the pairing mechanism between high-fLOD variants of forms A and $\mathrm{B}$ is kept absolutely strict and only one-to-one pairing is shown. That is, the pairs shown not only have the same window wall ratio and balcony type, but the same method is followed for distributing the glazing on various orientations. This results in 48 comparisons resulting from 48 façade design possibilities modelled at highfLOD. Pairs resulting in reversal of performance are marked as 'instances of opportunity loss'.

For the sDA metric (Figure 4(a)), at high-fLOD we find an appreciable range in possible relative performance outcomes $(+21.7 \%$ to $-10.7 \%)$ as compared to the

$$
E P R L=\left\{\begin{array}{ccc}
0.5 *\left|\int_{d}^{\infty} f_{R}(r) d r\right|, & \text { when }\left|a_{\text {min }}-b_{\text {min }}\right|<d \\
\int_{d-\sigma}^{d+\sigma}(d-R) f_{R}(r) d r, & \text { when }\left|a_{\text {min }}-b_{\text {min }}\right|>d \text { and } \operatorname{EOL}\left(A^{*}, B\right)<\frac{d}{2} \\
\operatorname{EOL}\left(A^{*}, B\right), & \text { otherwise }
\end{array}\right.
$$




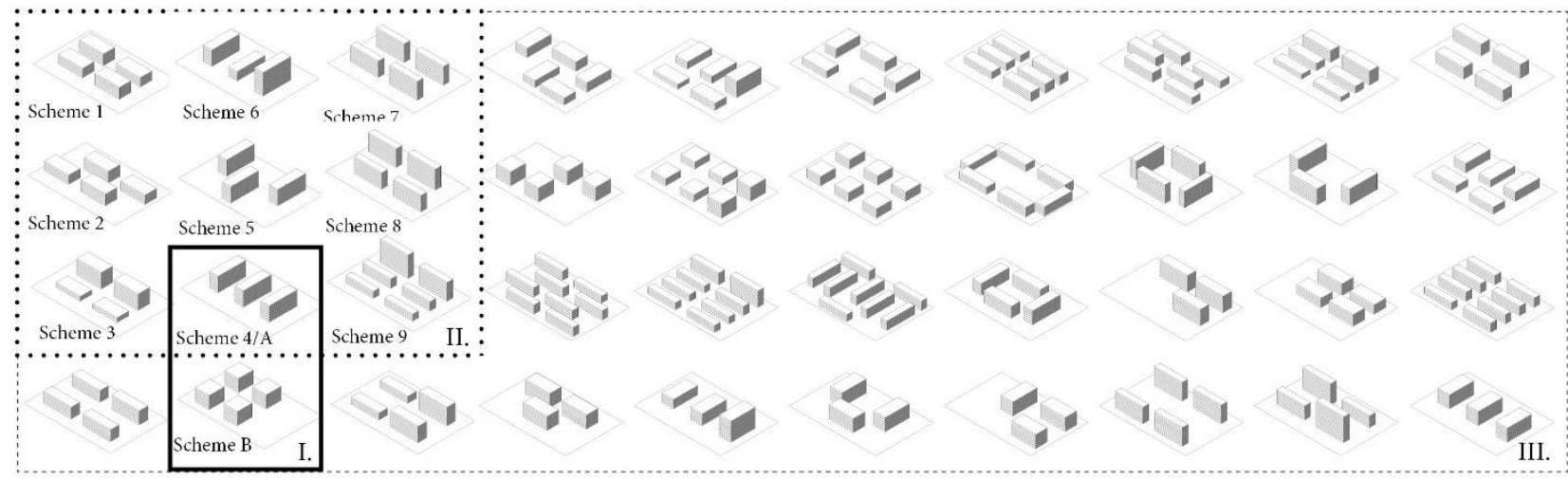

Figure 3: Set of massing schemes formulated into pairs for comparisons (total number $=40$ )

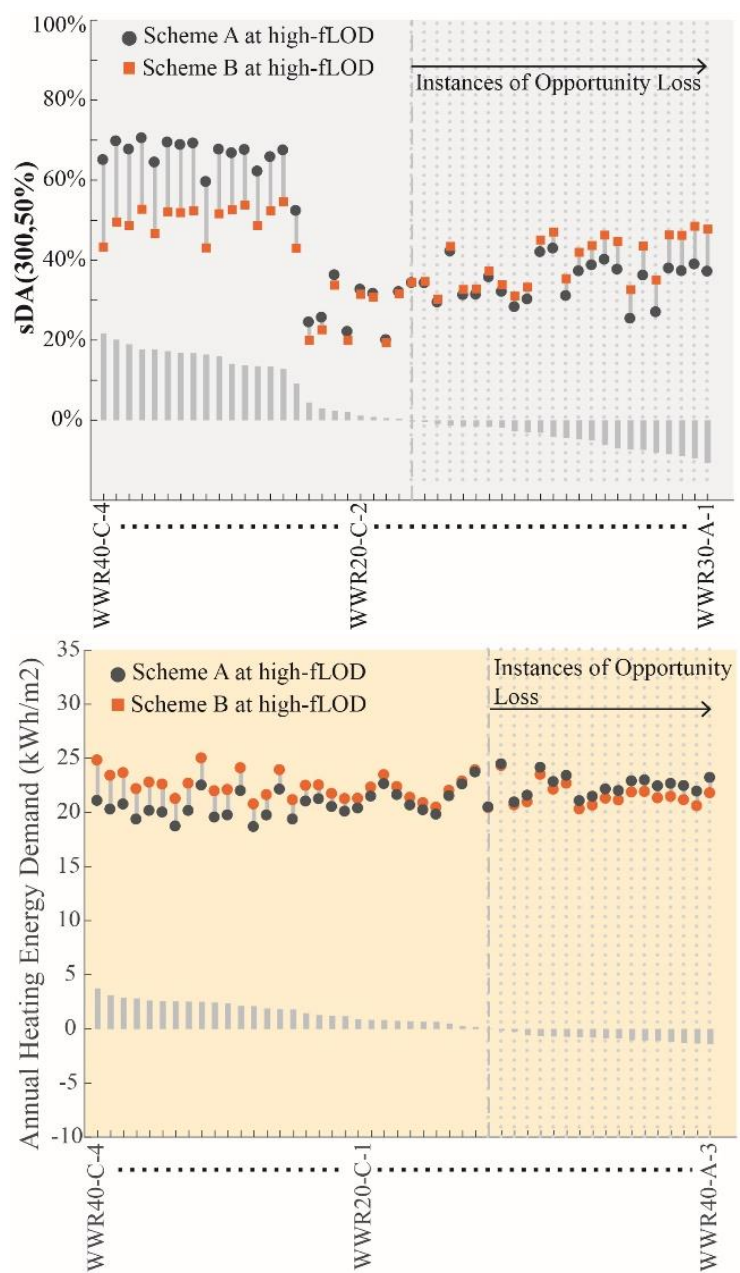

Figure 4: Strict one-to-one pair wise comparison of façade variants of massing scheme A(grey) and B(orange) at high $f L O D$. On the $x$-axis the façade variant type is listed with WWR $(20,30,40)$, prominent façade orientation decision algorithm (A,B,C,D) and balcony type $(1,2,3,4)$. Performance values shown for $S D A(a$; top) Heating Demand ( $b$; bottom)

observed difference in performance at low-fLOD $\left(\mathrm{A}_{\min ^{-}}\right.$ $\mathrm{B}_{\min }=10.2 \%$ ). That is, depending on the façade design type, performance difference between $\mathrm{A}$ and $\mathrm{B}$ could increase upto $21.7 \%$ or the higher performing massing scheme $\mathrm{A}$ could drop below its competing massing scheme B and result in a 'loss' of $10.7 \%$. We assume the threshold for high risk to be, $50 \%$ or greater chance of losing perform-

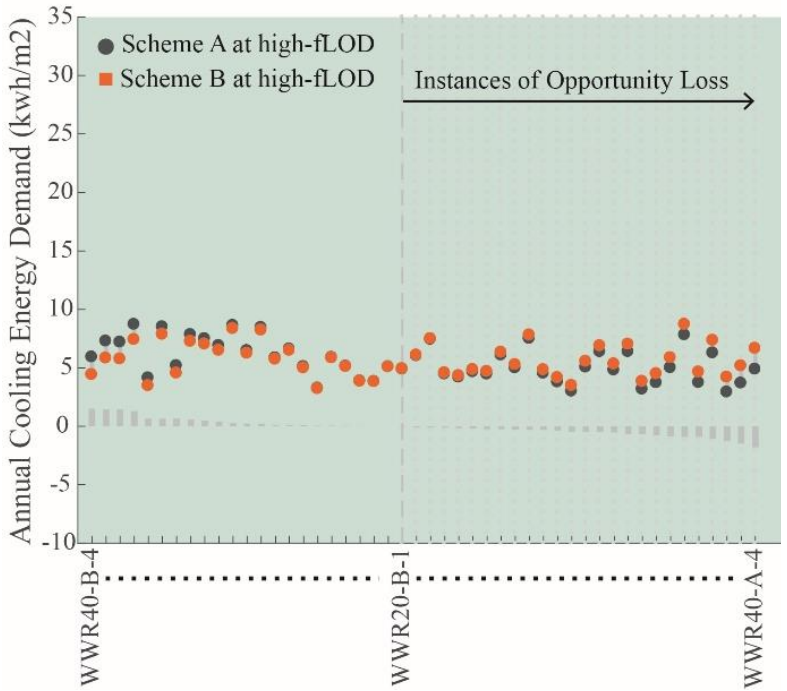

Figure 4 (continued): Cooling Demand (c)

-ance gain equal to the decision criterion. For example, the decision criterion for choosing a form based on sDA is set at $10 \%$. So a $50 \%$ chance of losing $10 \%(0.5 \times 10 \%=5 \%)$ on $\mathrm{SDA}$ is a high risk condition. We tested a range of threshold values of risk at min-fLOD that would ensure a risk of less than 5\% (sDA) on any design path that maybe taken in the future by the designer. Following the ERPL calculation methodology (see eq. 2) after collapsing all possible design paths results in a risk value of $3.3 \%$ for the presented example (A, B). The threshold for limiting upstream risk to maximum permissible value of $5 \%$, was found to be $2.1 \%$ loss in SDA at min-fLOD. We calculate similar threshold values for each metric and use them to normalize and categorize the ERPL for the final summary (Figure 6) as high risk cases. For the example comparison shown between schemes A, B the risk at min-fLOD is found to be high since it exceeds the high risk threshold. Negligible difference (difference in performance at minfLOD < decision criteria D) in heating and cooling demand is found between the forms $\mathrm{A}$ and $\mathrm{B}(-0.73 \mathrm{kWh} / \mathrm{m} 2$-year and $0.49 \mathrm{kwh} / \mathrm{m} 2$-year respectively). When we graduate to high-fLOD (Figure 4b,4c) for heating demand and cooling demand, even though there are instances of 'opportunity loss', the performance differences in the region of opportunity loss still remain negligible in magnitude. This is then reflected in a very low value ERPL of 0.2 and 0 $\mathrm{kWh} / \mathrm{m} 2$-year for heating and cooling demand 
respectively. These are clearly low risk cases. Table 2 also shows a comparison of massing schemes A, B based on a few geometrical properties along with the performance values on metrics mentioned above. Passive Zone Ratio (PZR) known to be an indicator for higher daylight availability is found consistent in this case. Surface to volume ratio is known as an indicator of heating demand in heating dominated climates. Given the small difference in surface to volume ratio between massing scheme A and $\mathrm{B}$, and the resulting negligible difference in heating demand, the results can again be said to be consistent in this case.

Table 2: Results for example Scheme A and B

\begin{tabular}{|c|c|c|c|c|}
\hline $\begin{array}{l}\text { Indicators and } \\
\text { performance at min- } \\
\text { fLOD }\end{array}$ & 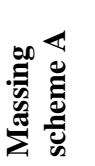 & 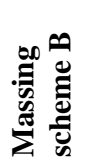 & 氖导 & $\overrightarrow{\underline{\vec{a}}}$ \\
\hline Surface-volume ratio & .22 & .20 & .02 & N/A \\
\hline Passive Zone Ratio & $85 \%$ & $73 \%$ & $12 \%$ & N/A \\
\hline $\begin{array}{ll}\text { Annual Irradiation } \\
(\mathrm{kWh} / \mathrm{m} 2) & \text { - facades }\end{array}$ & 582 & 592 & 3 & N/A \\
\hline $\begin{array}{ll}\begin{array}{l}\text { Sky view factor } \\
\text { (facades) }\end{array} & \\
\end{array}$ & 0.42 & 0.42 & 0 & N/A \\
\hline sDA (low-fLOD) & $74.9 \%$ & $64.7 \%$ & $10.2 \%$ & $3.3 \%$ \\
\hline $\begin{array}{l}\text { Annual Heating (min- } \\
\text { fLOD) }\end{array}$ & 16.75 & 17.48 & -0.73 & 0.2 \\
\hline $\begin{array}{l}\text { Annual Cooling (min- } \\
\text { fLOD) }\end{array}$ & 13.56 & 13.07 & 0.49 & 0 \\
\hline
\end{tabular}

In Figure 5 (a), (b), (c) we show the full set of relative comparisons possible between two forms at high-fLOD. The pairs of massing schemes shown are from Figure 2. Box II. Comparison is now shown (Figure 5), while still keeping WWR and balcony type the same between comparisons. However, Figure 5 only shows the instances and not the magnitude of opportunity loss. No instances of opportunity loss are observed on $6,4,3$ out of 9 comparisons on sDA, heating and cooling demand respectively.

Instances of opportunity loss on sDA (Figure 5 (a)) are largely limited to 'low' WWR (20-30\% WWR). It appears that risk is limited on SDA if the WWR for the project is of the order of $40 \% \mathrm{WWR}$. At high WWR other design factors do not have a large enough effect to cause reversal in performance values on the sDA criterion (300 lux, 50\% of occupied time). At low window wall ratio, the performance remains sensitive to the distribution of glazing by orientation and balcony type. This is not found to be the case for heating and cooling demand based comparison, where instances of opportunity loss are observed under all the cases. Opportunity loss cases appear to be more specific to façade design (distribution of glazing and balcony type), rather than the overall glazed area. We further expand our study to a substantially larger set of massing scheme comparisons to understand how often we are likely to incur a significant ERPL if making design decisions at min-fLOD. Figure 6. Shows ERPL value normalized by the respective risk threshold for each metric resulting a simple ratio. A value less than 1 as a low risk case based on the discussion in the context of scheme $\mathrm{A}$ and $\mathrm{B}$. Cases resulting in higher ratios carry a high risk

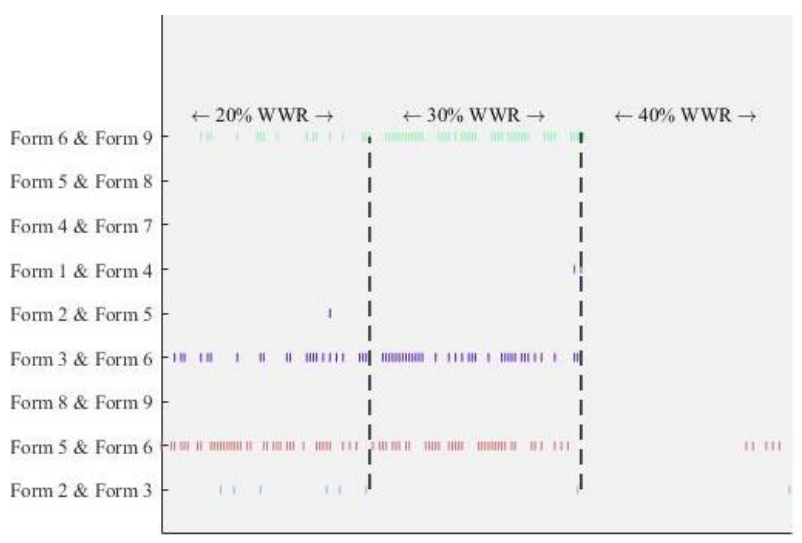

Instances of Opportunity Loss for sDA

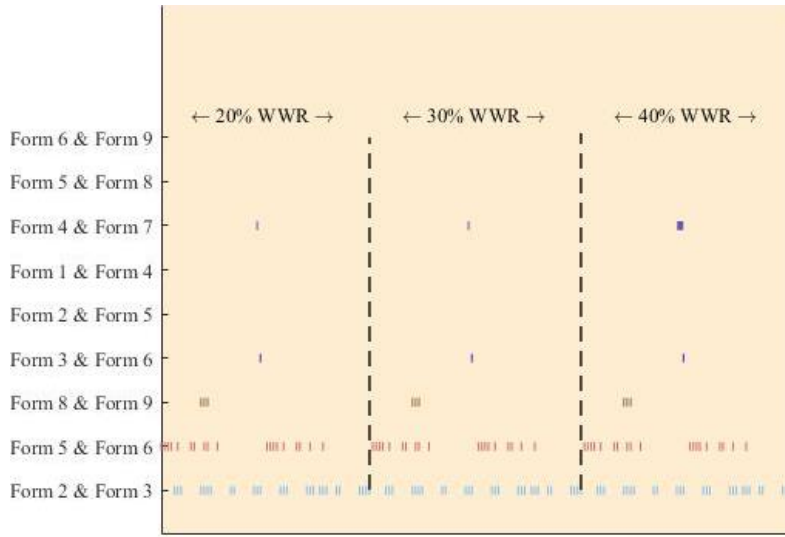

Instances of Opportunity Loss for Heating Demand

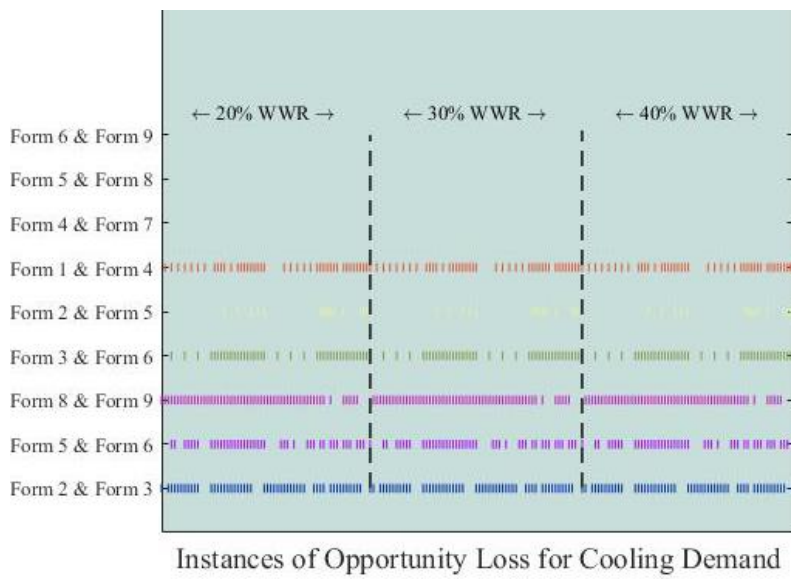

Figure 5 Occurrences of opportunity loss for 9 example pairs of competing massing schemes. Every marker represents one instance of opportunity loss on SDA (top)

Heating demand (bottom); Cooling demand (bottom)

in decision making and suggest a need for decision to be made only when higher level of façade details is available/input. In case of cooling demand based assessments $92 \%$ cases are found to fall under the low risk category, suggesting higher reliability in cooling demand based evaluations than for heating demand or sDA based evaluations.

As mentioned earlier, this study is limited to certain façade design decisions. Other façade related decisions such as glazing transmission properties may diminish or amplify 


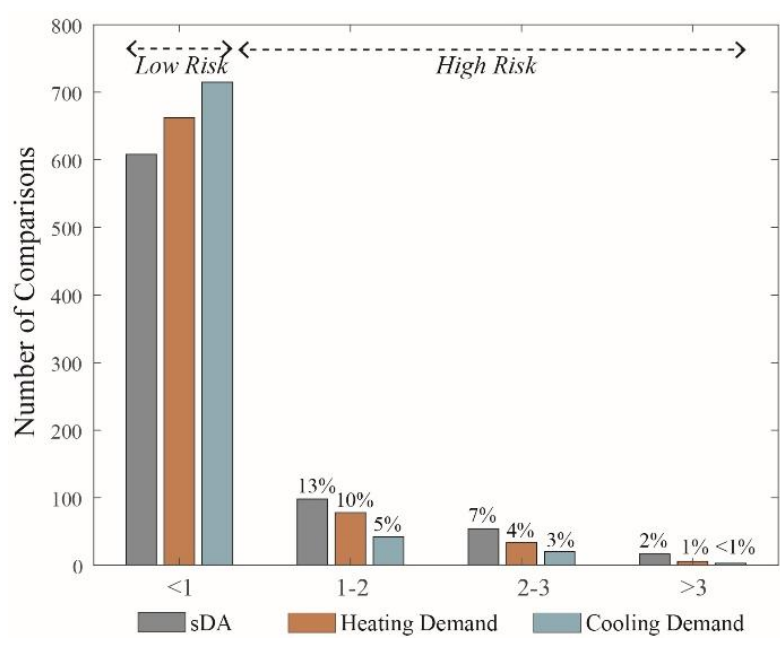

Figure 6: ERPL value for 780 comparisons normalized by risk threshold criteria for each metric

the performance difference between the two massing schemes being compared. This may in turn effect the resulting ERPL.

For example, much fewer cases of opportunity loss are found at high window wall ratio on SDA metric based evaluation, we anticipate that higher glazing transmittance properties can further diminish opportunity loss cases. However, if we regard the assumptions made in this study as representative of common practice, we find sufficient justification for carrying out performance evaluations when at least some façade attributes such as WWR are known, to reduce the risk of opportunity loss on sDA. In case of heating/cooling demand, knowledge of WWR is also not likely to reduce risk. This shall be further explored in future publications.

\section{Conclusions}

In this study we depart from uncertainty based measures used to support design decision making and identify a measure for isolating the risk of performance loss when making design choices under uncertainty. Uncertainty exploration can quantify confidence in performance estimated from BPS tools and are useful in understanding reliability of performance of each design choice. When making binary design choices, isolating the risk helps a decision maker estimate the likelihood of being incorrect based on the current state of design definition.

We adapted an existing risk measure - Opportunity Loss, to be applied to BPS based design assessments in a sequential building design process. We demonstrate its use for calculating risk in decision making at the conceptual design stage when building level façade design details are unknown but a higher performing massing scheme needs to be identified. By carrying out a number of comparisons on massing schemes $(\mathrm{N}=780)$ we found cooling demand assessments to be the most reliable at the conceptual design stage with $92 \%$ cases falling under the low risk category. Thus for the climate of Geneva, at code compliant level of envelope thermal insulation, lack of knowledge of façade design details resulted in significant opportunity loss in $8 \%$ cases. In sDA and cooling demand based assessments the reliability is found to be lower $(22 \%, 15 \%$ high risk cases respectively).

Risk measures presented in this study, not only show potential for measuring reliability of the performance metrics at the early design stage but can also be used attest the adequacy of level of design detail in 3D models. The Level of Development (LOD) specification and Building Information Models (BIM) are increasingly seen as the key tools for digitizing and formalizing the building design process. However, a critical evaluation of the processes adopted is vital before wide scale formalization efforts are introduced in order to ensure high performance building design. Methods presented in this study can be used to assess minimum level of design development needed before performance evaluations can be done reliably.

\section{Acknowledgement}

We sincerely thank Dr. Marc-Olivier Boldi at Université de Lausanne, Switzerland for assistance in identification and use of the particular methodology used in this study.

\section{References}

Biljecki, Filip, Hugo Ledoux, and Jantien Stoter. 2016. "An Improved LOD Specification for 3D Building Models and Its CityGML Realisation with the Random3Dcity Procedural Modelling Engine." Computers, Environment and Urban Systems (Submitted).

Brembilla, Eleonora, Christina Hopfe, and John Mardaljevic. 2017. "Influence of Input Reflectance Values on Climate-Based Daylight Metrics Using Sensitivity Analysis." Journal of Building Performance Simulation, 1-17.

Clarke, J. A., and J. L. M. Hensen. 2015. "Integrated Building Performance Simulation: Progress, Prospects and Requirements." Building and Environment, Fifty Year Anniversary for Building and Environment, 91 (September): 294-306.

Clarke, Joe. 2015. "A Vision for Building Performance Simulation: A Position Paper Prepared on Behalf of the IBPSA Board." Journal of Building Performance Simulation 8 (2): 39-43.

Compagnon, R. 2004. "Solar and Daylight Availability in the Urban Fabric." Energy and Buildings 36 (4): 32128.

Crawley, Drury B., Curtis O. Pedersen, Linda K. Lawrie, and Frederick C. Winkelmann. 2000. "EnergyPlus: Energy Simulation Program." ASHRAE Journal 42: 49-56.

Hester, Joshua, Jeremy Gregory, and Randolph Kirchain. 2017. "Sequential Early-Design Guidance for Residential Single-Family Buildings Using a Probabilistic Metamodel of Energy Consumption." Energy and Buildings 134 (Supplement C): 202-11.

Hopfe, Christina J., Godfried L.M. Augenbroe, and Jan L.M. Hensen. 2013. "Multi-Criteria Decision Making under Uncertainty in Building Performance Assessment." Building and Environment 69 (November): 81-90. 
Hubbard, Douglas. 2014. How to Measure Anything: Finding the Value of Intangibles in Business. 3rd ed. John Wiley \& Sons.

IESNA. 2012. IES LM- 83-12, Approved Method: IES Spatial Daylight Autonomy (SDA) and Annual Sunlight Exposure (ASE). IESNA Lighting Measurement. New York, NY, USA.

Iversen, A, S Svendsen, and TR Nielsen. 2013. "The Effect of Different Weather Data Sets and Their Resolution on Climate-Based Daylight Modelling." Lighting Research \& Technology 45 (3): 305-16.

"LEED | USGBC." Accessed January 6, 2018. https://new.usgbc.org/leed.

"LOD | BIMForum.” Accessed May 9, 2019. https://bimforum.org/lod/.

Nault, Emilie. 2016. "Solar Potential in Early Neighborhood Design. A Decision-Support Workflow Based on Predictive Models." PhD Thesis, Lausanne, Switzerland: Ecole polytechnique fédérale de Lausanne.

Nezamdoost, Amir, and Van Dan Wymelenberg. 2016. "Sensitivity Study of Annual and Point-in-Time Daylight Performance Metrics: A 24 Space MultiYear Field Study." In Proceedings of SimBuild 2016. Vol. 1.

Reinhart, Christoph, Timur Dogan, J. Alstan Jakubiec, Tarek Rakha, and Andrew Sang. 2013. "Umi-an Urban Simulation Environment for Building Energy Use, Daylighting and Walkability." In Proceedings of Building Simulation (IBPSA), 476-483. Chambéry, France.

http://web.mit.edu/SustainableDesignLab/publication s/umi_introduction.pdf.

Reinhart, Christoph F. 2012. DAYSIM. Cambridge, MA, USA. http://daysim.ning.com.

Robinson, D., N. Campbell, W. Gaiser, K. Kabel, A. LeMouel, N. Morel, J. Page, S. Stankovic, and A. Stone. 2007. "SUNtool - A New Modelling Paradigm for Simulating and Optimising Urban Sustainability." Solar Energy 81 (9): 1196-1211.

Robinson, Darren, Frédéric Haldi, J. Kämpf, Philippe Leroux, Diane Perez, Adil Rasheed, and Urs Wilke. 2009. "CitySim: Comprehensive Micro-Simulation of Resource Flows for Sustainable Urban Planning." In Proceedings of Building Simulation (IBPSA). Glasgow, Scotland.

Savage, L. J. 1951. "The Theory of Statistical Decision." Journal of the American Statistical Association 46 (253): 55-67.

SIA. 2016. "Norme 380/1-2016: Besoins de Chaleur Pour Le Chauffage." Zurich, Switzerland: Swiss Society of Engineers and Architects (SIA).

Smith, Preston G., and Guy M. Merritt. 2002. Proactive Risk Management: Controlling Uncertainty in Product Development. 1st ed. Productivity Press.

Su, Hsin-Ting, and Yeou-Koung Tung. 2012. "Minimax Expected Opportunity Loss: A New Criterion for Risk-Based Decision Making." The Engineering Economist 57 (4): 247-73.
Tregenza, PR. 2017. "Uncertainty in Daylight Calculations." Lighting Research \& Technology 49 (7): 829-44. 